\title{
DRUG PRESCRIPTION PATTERN OF BREAST CANCER PATIENTS IN A TERTIARY CARE HOSPITAL IN WEST BENGAL: A CROSS-SECTIONAL AND QUESTIONNAIRE-BASED STUDY
}

\section{ANJAN ADHIKARI ${ }^{1 *}$, DIPESH CHAKRABORTY ${ }^{2}$, RANIA INDU ${ }^{1}$, SANGITA BHATTACHARYA ${ }^{1}$, MOUMITA RAY ${ }^{1}$, RAMANUJ MUKHERJEE ${ }^{3}$}

${ }^{1}$ Department of Pharmacology, R. G. Kar Medical College, Kolkata - 700 004, West Bengal, India. 2Department of Pharmacology, Bengal School of Technology, Hooghly - 712 102, West Bengal, India. 3Department of Surgery, R. G. Kar Medical College, Kolkata - 700 004, West Bengal, India. Email: dradhikarianjankolkata@gmail.com

Received: 18 October 2017, Revised and Accepted: 14 December 2017

\section{ABSTRACT}

Objective: Cancer is a disease of uncontrolled division of cells in any part of the body. Breast cancer most common in women accounts for $13 \%$ of the death worldwide. The objective of the present study was to evaluate the drug prescription pattern of breast carcinoma patients in a tertiary care hospital of West Bengal.

Methods: This was a cross-sectional observational questionnaire-based study done for a period of 6 months at the Department of Pharmacology in Collaboration with the Department of Surgery and Department of Radiotherapy of a Tertiary Care Hospital at Kolkata, West Bengal, India. Female patients with breast cancer (originated from epithelial tissues) of different types and grade attending surgery outdoor patient department were taken as subjects for the study, after signing informed consent.

Results: The present study evaluated 28 patients $(n=28)$ diagnosed as breast cancer by the physicians of the department of surgery and radiotherapy. It was observed that breast cancer was mostly found in the middle age group. Breast carcinoma in postmenopausal women accounted to $75 \%$. The most prevalent breast cancer was invasive ductal carcinoma, accounting to $75 \%$ of the study population. 5-Fluorouracil, epirubicin, doxorubicin, cyclophosphamide, docetaxel/paclitaxel, and carboplatin were mostly used as chemotherapeutic agent.

Conclusion: Breast carcinoma being a prevalent type of cancer in females, the present study tried to evaluate the pattern of prescribing chemotherapeutic agents for breast cancer patients in a tertiary care hospital. Such study is essential to evaluate and refine the therapeutic regimen of the cancer patients to reduce their sufferings.

Keywords: Allred score, Breast carcinoma, Nottingham factor, Prescription.

(C) 2018 The Authors. Published by Innovare Academic Sciences Pvt Ltd. This is an open access article under the CC BY license (http://creativecommons. org/licenses/by/4. 0/) DOI: http://dx.doi.org/10.22159/ajpcr.2018.v11i3.23180

\section{INTRODUCTION}

Cancer is a life-threatening disease which causes to lose cohesiveness and orderliness of normal tissue [1]. Apoptosis or programmed cell death in normal tissues is replaced by uncontrolled cell growth in cancer cells [2]. The cells which grow uncontrollably are called malignant cells and the phenomenon of converting a normal cell to malignant cell is called "malignancy." These malignant cells can spread to any other organ through blood flow or lymphatic flow and develop malignancy over there, this phenomenon is called metastasis [3]. Malignant cells can also invade the surrounding tissue. Lung cancers, skin cancer, colorectal cancer, bladder cancer, and breast cancer are the most common cancers, globally. Statistics till 2016 estimated that about 16.8 lakh people are suffering from cancer in the United States [4]. In India, around 2.5 million people are affected with this disease [5].

Breast cancer is the leading cause of cancer-related mortality in women causing $13 \%$ death around the globe [6]. Breast cancer initiates when cells in the breast begin to grow uncontrollably. Risk factors of developing the breast cancer include early menarche, late menopause, genetic and epigenetic reasons, family history of breast cancer, race and ethnicity, having dense breast tissue, drinking alcohol, and being overweight or obese. [7]. In India, breast cancer accounts for $27 \%$ of all types of cancer among woman [5].

Theprognosis and stage of cancercells can be detected bystainingprocess, known as immunohistochemistry. A scoring system, the Nottingham prognostic index (NPI) is allotted based on these histopathological factors such as tumor size, lymph node stage, and tumor grade. NPI can identify the disease progression and how aggressive the cancer is. The scoring system is based on the differentiation of the cancer cells, i.e., how much it resembles the normal tissue. Well-differentiated cancer cells look more like the normal cells and grow slowly, whereas poorly differentiated cancer cells are more aggressive and metastasize more quickly. The scoring system is as follows:

- 3-5 points: Grade I - Well differentiated

- 6-7 points: Grade II - Moderately differentiated

- $\quad-9$ points: Grade III - Poorly differentiated [8].

Hormones such as estrogen and progesterone play a major role in the prognosis of this disease. Disturbances in the homeostasis of hormones in the body are responsible for the advancement of this disease. Most of the breast cancer cells show predominant expression of receptors for these hormones. Human epidermal growth factor receptor 2 (HER2) receptors are also seen in few cancer cells. The success of hormonetargeted therapy depends on the nature of these receptors. However, few breast cancer cells fail to express any types of receptors are termed as triple negative cancers. Another scoring system, Allred score is allotted based on the staining of these hormone receptors. The proportion of stained cells for hormone receptor (scored on a scale of $0-5$ ) and staining intensity (scored on a scale of 0-3) was considered into this scoring system. Total score was obtained by adding the proportion and intensity. High score signifies the presence of many hormone receptors, and thus, cells are responsive to hormone treatments with drugs like tamoxifen [9]. 
Global and national studies revealed the sufferings of breast cancer. A number of drugs such as 5-fluorouracil, epirubicin, doxorubicin, cyclophosphamide, docetaxel/paclitaxel, and carboplatin are prescribed to tackle such type of patients. However, till date, there is no universally accepted guideline for better therapeutic management. Thus, there is a need to explore the drug prescribing pattern of these cancer patients. The present study described the pattern of breast carcinoma and also the drug prescribed in a tertiary care hospital, Kolkata, India.

\section{METHODS}

The present study was a cross-sectional observational questionnairebased study, conducted from December 2016 to June 2017, at surgery outdoor patient department (OPD) and Department of Radiology of R. G. Kar Medical College and Hospital at Kolkata. Female patients diagnosed with breast carcinoma of different types and grade, attending surgery OPD and Department of Radiology, were included in the study. The study was cleared ethically by the Institutional Ethics Committee (RKC/5439 dated 14.12.2016), and then, those patients willing to sign the written informed consent form were included in the study. The menopausal status of the patients was identified. The type of carcinoma, the correlation of the time gap between untreated noticeable lump and initiation of treatment with the grade of tumor, Nottingham score, and the Allred score of the cancers were noted. The drugs prescribed to the patients were also evaluated.

\section{RESULTS}

The present study population included 28 breast cancer patients of different stage, with an average age of 51 years $( \pm 10.5)$ ranging from 28 to 73 years, average weight of $55.3 \mathrm{~kg}( \pm 8.68)$ ranging from 40 to $78 \mathrm{~kg}$, and average body surface area (BSA) of $1.47 \mathrm{~m}^{2}$ as baseline.

Comparison of pre- and post-menopausal status of the patients revealed 7 (25\%) were premenopausal and 21 (75\%) were post-menopausal. As per type of carcinoma, 21 of the cases were of invasive ductal carcinoma (IDC) (25\%), 4 cases of ductal carcinoma in situ (DCIS) (14\%), 2 cases of triple negative breast cancer (7\%), and 1 case of invasive lobular carcinoma (4\%). Carcinoma in the right breast $61 \%$ (17) was higher as comparison to the left breast 39\% (11).

The presence of hormonal receptors in the study population was evaluated and reported in Fig. 1. Majority of the patients (11, 42.3\%) were found to contain both estrogen and progesterone receptors (PRs). Only estrogen receptor (+ve) breast tumor lesion was found in 8 cases (30.8\%). 2 (7.7\%) patients were found to be HER2 neu receptor positive. Triple negative was in 3 cases (11.5\%), and estrogen, progesterone, and HER2 neu receptor were present in 2 cases (7.7\%). Immunohistochemistry results were not obtained for two cases, so total study population in this case was $26(\mathrm{n}=26)$.

Progression of disease and status of abnormality of the tumor cells are expressed in terms of grade of the tumor. It is presumed that negligence in detection and treatment might influence the disease progression. Therefore, in the present study, the grade of tumor, at the time of diagnosis, was plotted against the time gap of noticing the lump and initiation of treatment. Statistical analysis showed that there was an insignificant correlation $(2.2 \%)$ between time gap of untreated noticeable lump and initiation of treatment with the grade of tumor.

The present study tried to investigate the correlation between the differentiation of the cells through Nottingham score with that of the prevalence of hormonal receptors, expressed in term of Allred score. Thus, from the linear plot of Nottingham score and the corresponding Allred score (Fig. 2), it was observed that coefficient of determination (R2) was 0.0129, i.e., the Allred score influenced the Nottingham scoring of a tumor by $1.29 \%$. Therefore, no significant correlation was observed between the stage of differentiation of the cancer cells and the presence of hormonal receptors.
The study population was categorized according to the primary symptoms of the diseases. $61 \%$ of the study population were having painless lump, $28 \%$ were having painful breast lump, and $12 \%$ were having primarily painless and then painful lump, at the time of selfidentification of the disease. It was to be noticed that one subject presented with ulcerated breast with swollen up nodes, followed by foul smell. Some of the patients having pain as primary symptoms experienced and had a complaint of frequent headache, pain in underarms, pain in neck, and elbow pain.

Treatment of the breast cancer depends on the stage and type of the tumor. Lumpectomy is regarded as removal of the lump only, whereas surgical removal of the entire breast is termed as mastectomy [7]. In the present study population, 24 patients among 28 had mastectomy (simple, full, and partial), and others had lumpectomy. Mastectomies were performed for advanced disease, more than one tumor or for relatively small breast where obtaining negative margin was not possible.

Drugs used in the present study were documented in Fig. 3. The most common drug used in the present study was cyclophosphamide (20\%), followed by docetaxel (13\%), doxorubicin (12\%), 5-fluorouracil (12\%), paclitaxel (9\%), epirubicin (9\%), tamoxifen $(8 \%)$, letrozole $(7 \%)$, trastuzumab (6\%), and carboplatin (4\%). The most commonly used route of administration was intravenous. The anatomical therapeutic chemical (ATC code) and route of administration of these drugs were tabulated in Table 1.

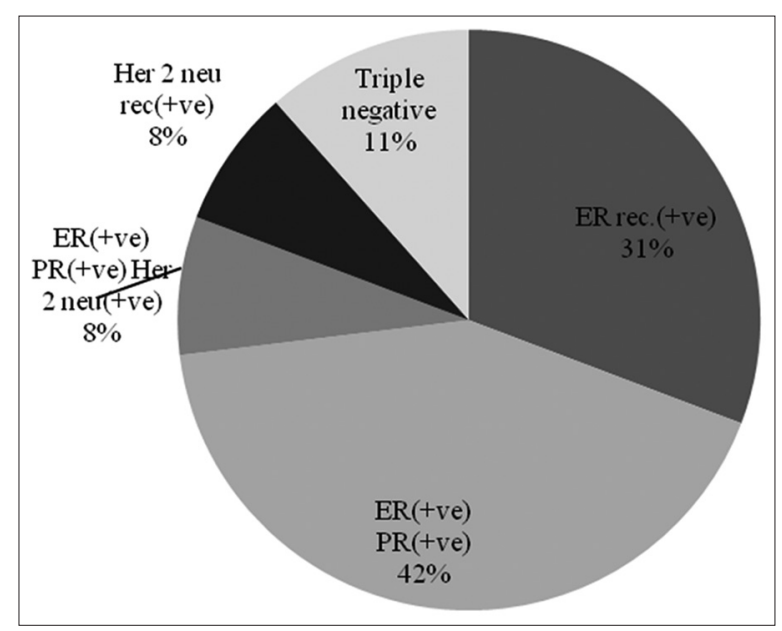

Fig. 1: Distribution of hormonal status of the study population $(n=26)$

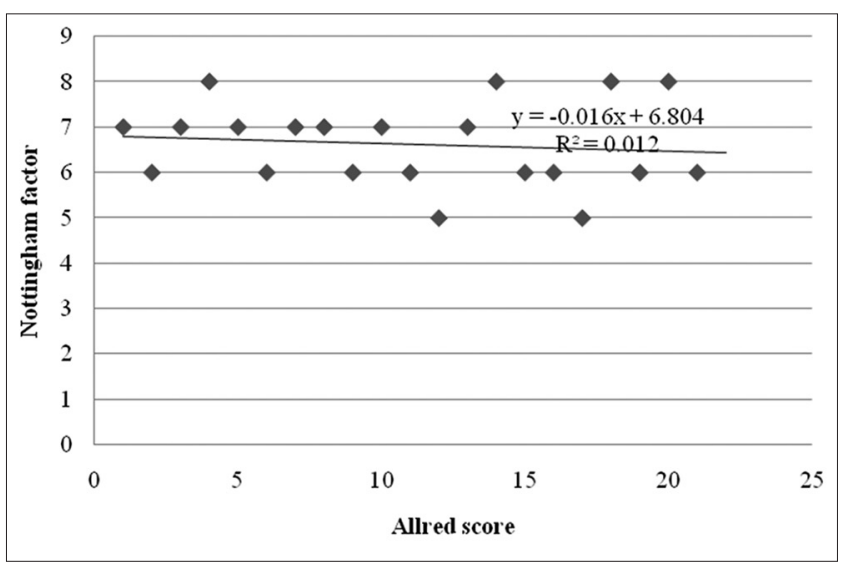

Fig. 2: Graphical representation of Nottingham scoring of the disease and corresponding Allred scoring $(n=28)$ 


\section{DISCUSSION}

Cancer cells are formed due to abnormal growth of normal cells because of mutation of DNA. Among the different types of cancers, breast cancer is most prevalent among the woman [10]. The present study was conducted on breast cancer patients attending a tertiary care hospital in Kolkata, West Bengal, India, to evaluate the pattern of breast carcinoma and therapeutic regimen provided to them.

The study population comprised of 28 breast cancer patients. The mean age of the population was 51 years $( \pm 10.5)$ ranging from 28 to 73 years with the average weight of $55.3 \mathrm{~kg}( \pm 8.68)$ ranging from 40 to $78 \mathrm{~kg}$. A survey on breast cancer patients in Manipal, India, estimated that the study participants belonged to the age group of 25-69 years [11]. A similar study among Turkish woman revealed the age ranged from 18 to 70 years [12]. A study in Iran showed that the average age of breast cancer patients was 47.49 years that was comparable with the present study [13]. In the present study, the average BSA was $1.47 \mathrm{~m} 2$. Statistics from the United Kingdom revealed that the mean BSA was about $1.79 \mathrm{~m}^{2}$ [14].

Hormones such as estrogen and progesterone play a major role in the prognosis of this disease. Disturbances in the homeostasis of hormones in the body are responsible for the advancement of this disease. Most of the breast cancer cells show predominant expression of receptors for these hormones. HER2 receptors are also seen in few cancer cells. Success of hormone-targeted therapy depends on the nature of these

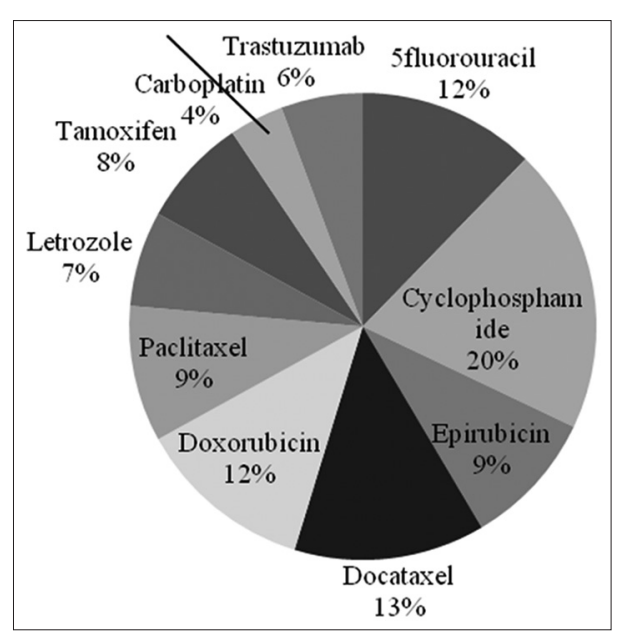

Fig. 3: Distribution of the prescribed drugs in the study population $(n=28)$ receptors. However, few breast cancer cells fail to express any types of receptors are termed as triple negative cancers. Triple negative cancers are related to poor prognosis of the disease as no hormonetargeted therapy is useful $[15,16]$. Menopausal status is associated with the prognosis of this disease. Research showed that delay in menopause incurs a risk for developing breast cancer. Moreover, breast cancers diagnosed at a younger age have aggressive clinicopathologic features. Studies have revealed that postmenopausal woman with high serum concentrations of sex hormones carries a greater propensity of developing breast cancer [17]. Distribution of the present study population by their menopausal status found that $25 \%$ (7) of the patients were premenopausal and 75\% (21) were postmenopausal. Average age of breast cancer patients, who were postmenopausal, was 55.28 years $( \pm 8.18)$ and that for women in premenopausal state was 38.85 years $( \pm 6.44)$. A national study among breast cancer patients in a tertiary care hospital in South India reported that $48 \%$ belonged to premenopausal state and $52 \%$ had reached menopause [18]. Similar study in Lahore reported that $42.7 \%$ were premenopausal and $57.3 \%$ postmenopausal [19].

Among the different forms of breast cancer obtained in the present study, the most prevalent were IDC, accounting to $75 \%$ of the study population. This was supported by other studies that highlighted IDC was the most common form of breast cancer, representing 80 percent of all breast cancer [11]. A study from New Delhi observed that IDC was the most common type (88\%), followed by infiltrating lobular carcinoma (3.7\%), colloid carcinoma (1.1\%), DCIS $(1.1 \%)$, and metaplastic types (0.9\%) [20]. IDC mostly expresses the estrogen receptor (ER)+PR+cancer. Among the 21 cases of IDC, 10 patients had $\mathrm{ER}+, 9$ had ER+PR+, and 2 cases of HER 2neu+ve.

Triple negative carcinoma accounted for $7 \%$ of the present study population that was much lower as compared to studies from North and South India, where the percentages were 18\% [21] and 31.5\% [22], respectively. Thus, most of the patients in the present study population responded better in hormonal therapy. The treatment schedule included surgery followed by chemotherapy depending on the current status of the disease and entire breast radiotherapy. This type of tumor does not respond to hormonal treatment and therefore not recommended.

It is presumed that negligence in treatment might influence the disease progression. However, in the present study, no significant correlation was observed between time gap of untreated noticeable lump and initiation of treatment with the grade of tumor.

The patients in the study population were categorized according to the primary symptoms of the diseases. Distribution of study population

Table 1: Distribution of ATC classification of prescribed drugs along with their route of administration

\begin{tabular}{|c|c|c|c|}
\hline Generic name of the drug & ATC code & Classification & Route of administration \\
\hline 5-Fluorouracil & L01BC02 & $\begin{array}{l}\text { Antineoplastic immunomodulating agent, antimetabolite, pyrimidine } \\
\text { analogue }\end{array}$ & IV \\
\hline Doxorubicin & L01DB01 & $\begin{array}{l}\text { Antineoplastic immunomodulating agent, cytotoxic antibiotics, } \\
\text { anthracycline derivative }\end{array}$ & IV \\
\hline Epirubicin & L01DB03 & $\begin{array}{l}\text { Antineoplastic immunomodulating agent, cytotoxic antibiotics, } \\
\text { anthracycline derivative }\end{array}$ & IV \\
\hline Cyclophosphamide & L01AA01 & $\begin{array}{l}\text { Antineoplastic immunomodulating agent, alkylating agent, nitrogen } \\
\text { mustard analog }\end{array}$ & IV \\
\hline Docetaxel & L01CD02 & Antineoplastic immunomodulating agent, plant alkaloid, taxane & IV \\
\hline Paclitaxel & L01CD01 & Antineoplastic immunomodulating agent, plant alkaloid, taxane & IV \\
\hline Tamoxifen & L02BA01 & $\begin{array}{l}\text { Antineoplastic immunomodulating agent, hormone antagonist, selective } \\
\text { estrogen receptor modulator }\end{array}$ & Oral \\
\hline Trastuzumab & L01XC03 & Antineoplastic, monoclonal antibody & IV \\
\hline Carboplatin & L01XA02 & Antineoplastic, platinum compound & IV \\
\hline Letrozole & L02BG04 & $\begin{array}{l}\text { Antineoplastic immunomodulating agen, endocrine therapy, aromatase } \\
\text { inhibitor }\end{array}$ & Oral \\
\hline
\end{tabular}

ATC: Anatomical therapeutic chemical, IV: Intravenous 
according to the symptoms showed that $61 \%$ of patients presented without pain, $28 \%$ experienced painful lump, and $11 \%$ reported it to be painless initially, followed by painful. Only one patient had ulcerated breast cancer with foul smell.

The chemotherapeutic drugs used in the present study were documented. The most common drug used in the present study was cyclophosphamide (20\%), followed by docetaxel (13\%), doxorubicin (12\%), 5-fluorouracil (12\%), paclitaxel (9\%), epirubicin (9\%), tamoxifen $(8 \%)$, letrozole $(7 \%)$, trastuzumab $(6 \%)$, and carboplatin (4\%). A study in Nigerian Tertiary Hospital revealed that $38 \%$ of breast cancer patients were prescribed the combination of cyclophosphamide, methotrexate, and 5 fluorouracil [23], whereas a study in Chandigarh, India, reported that $41.58 \%$ of patients were prescribed fluorouracil+doxorubicin+cyclophosphamide, while paclitaxel was prescribed to $22.77 \%$ of patients [24].

\section{CONCLUSION}

The risk of breast cancer is alarming, especially in developing countries like India. The present study was conducted on breast cancer patients attending a tertiary care hospital in Kolkata, West Bengal, India, to evaluate the pattern of breast carcinoma and therapeutic regimen provided to the patients. This type of study is essential to evaluate the epidemiological profile of the disease, the risk factors associated with them, and the treatment provided to these cancer patients. Awareness about the screening procedure and treatment of breast cancer among common people can be helpful in reducing the mortality of this disease.

\section{CONFLICTS OF INTERESTS}

None

\section{REFERENCES}

1. Shyamala K, Girish HC, Murgod S. Risk of tumor cell seeding through biopsy and aspiration cytology. J Int Soc Prevent Communit Dent 2014;4:5-11

2. Elmore S. Apoptosis: A review of programmed cell death. Toxicol Pathol 2007;35:495-516.

3. Seyfried TN, Huysentruyt LC. On the origin of cancer metastasis. Crit Rev Oncog 2013;18:43-73.

4. Siegel RL, Miller KD, Jemal A. Cancer statistics. CA Cancer J Clin 2016;66:7-30

5. Available from: http://www.cancerindia.org.in/cp/index.php/knowabout-cancer/statistics. [Last accessed on 2017 Jun 15].

6. WHO (October 2010) Cancer'. World Health Organization. Available from:[Last accessed on 2017 Jun 02].

7. Iyer M, Kumar PS, Karthikeyan S, Namboori PK. 'BRCA1' responsiveness towards breast cancer-a population-wise pharmacogenomic analysis. Int J Pharm Pharm Sci 2016;9:267-70.

8. Green AR, Soria D, Powe DG, Nolan CC, Aleskandarany M,
Szász MA, et al. Nottingham prognostic index plus (NPI+) predicts risk of distant metastases in primary breast cancer. Breast Cancer Res Treat 2016;157:65-75

9. Daltoé RD, Madeira KP, de Carvalho AA, de Rezende LC, Silva IV, Rangel LB. Evaluation of the progesterone receptor status in breast cancer using three different antibodies: A comparison by Allred score system. Int J Clin Exp Pathol 2014;7:331-9.

10. Reddy D, Kalyani G, Pradeep K, Asif M, Kartheek D, Gangabhavani M. The survey of cancer patients in the region of Guntur: Based on hospital registry. Int J Pharm Pharm Sci 2017;9:288-32.

11. Kamath R, Mahajan KS, Ashok L, Sanal TS. A study on risk factors of breast cancer among patients attending the Tertiary care hospital, in Udupi District. Indian J Community Med 2013;38:95-99.

12. Ozmen V, Ozcinar B, Karanlik H, Cabioglu N, Tukenmez M, Disci R, et al. Breast cancer risk factors in Turkish women a university hospital based nested case control study. World J Surg Oncol 2009;7:37.

13. Abbasi S, Azimi C, Othman F, Einollahi N, Dashti N, Nabatchian F, et al. Risk factors for breast cancer in Iranian women: A case control study. Int J Cancer Res 2009;5:1-11.

14. Sacco JJ, Botten J, Macbeth F, Bagust A, Clark P. The average body surface area of adult cancer patients in the UK: A multicentre retrospective study. PLoS One 2010;5:e8933.

15. Soonmyung P, Gong T, Steven S, Chungyeul K, Joffre B, Wanseop K, et al. Gene expression and benefit of chemotherapy in women With node-negative, estrogen receptor-positive breast cancer. J Clin Oncol 2006;24:3726-34

16. Rebecca D, Maureen T, Kathleen IP, Wedad MH, Harriet KK, Carol AS, et al. Triple-negative breast cancer: Clinical features and patterns of recurrence. Clin Cancer Res 2007;13:4429-34.

17. Key T, Appleby P, Barnes I, Reeves G, Endogenous Hormones and Breast Cancer Collaborative Group. Endogenous sex hormones and breast cancer in postmenopausal women: Reanalysis of nine prospective studies. J Natl Cancer Inst 2002;94:606-16.

18. Surakasula A, Nagarjunapu GC, Raghavaiah KV. A comparative study of pre-and post-menopausal breast cancer: Risk factors, presentation, characteristics and management. J Res Pharm Pract 2014;3:12-18.

19. Butt Z, Haider SF, Arif S, Khan MR, Ashfaq U, Shahbaz U, et al. Breast cancer risk factors: A comparison between pre-menopausal and postmenopausal women. J Pak Med Assoc 2012;62:120-4.

20. Saxena S, Rekhi B, Bansal A, Bagga A, Chintamani, Murthy NS. Clinico-morphological patterns of breast cancer including family history in a New Delhi hospital, India - A cross-sectional study. World J Surg Oncol 2005;3:67.

21. Dogra A, Doval DC, Sardana M, Chedi SK, Mehta A. Clinic pathological characteristics of triple negative breast cancer at a tertiary care hospital in India. Asian Pac J Cancer Prev 2014;15:10577-83.

22. Reddy GM, Suresh PK, Pai RR. Clinic pathological features of triple negative breast carcinoma. J Clin Diagn Res 2017;11:EC05-8.

23. Adisa A, Arowolo O, Akinkuolie A, Alatise OI, Lawal OO, Adesunkanmi AK, et al. Metastatic breast cancer in a Nigerian tertiary hospital. Afr Health Sci 2011;11:279-284

24. Saini VK, Sewal RK, Ahmad Y, Medhi B. Prospective observational study of adverse drug reactions of anticancer drugs used in cancer treatment in a tertiary care hospital. Indian J Pharm Sci 2015;77:687- 93. 